\title{
Pengaruh Latihan Pick-Up Sprint Dan Lari Dengan Usaha Maksimal terhadap Hasil Kecepatan Lari 100 Meter Atlet Putra Atletik Club Unimed Tahun 2020
}

\section{The Effect of Pick-Up Sprint and Running Exercises with Maximum Effort on the Results of the 100-meter Running Speed of Unimed Athletic Club Men's Athletes in 2020}

\author{
Muhammad Rommy Putra \\ Fakultas Ilmu Keolahragaan, Universitas Negeri Medan \\ Email: rommyputrachanigo@gmail.com
}

\begin{abstract}
ABSTRAK
Penelitian ini bertujuan untuk mengetahui ada tidaknya pengaruh latihan pick up sprint dan lari dengan usaha maksimal terhadap hasil kecepatan atletik lari atlet putra lari $100 \mathrm{~m}$ klub unimed tahun 2020. Metode yang digunakan dalam penelitian ini adalah metode eksperimental dengan pelaksanaan latihan yaitu pick up sprint dan lari dengan tenaga maksimal. Populasi dalam penelitian ini adalah seluruh atlet putra cabang lari $100 \mathrm{~m}$ unimed club tahun 2020 yang berjumlah 4 orang. Sampel diambil dari populasi dengan teknik total sampling. Sampel yang diambil dari penelitian ini sebanyak 4 orang. Instrumen penelitian untuk pengumpulan data dengan tes dan pengukuran run test $100 \mathrm{~m}$. Penelitian dilakukan selama 6 minggu dengan latihan 3 kali seminggu. Untuk melihat masing-masing variabel independen dan dependen digunakan perhitungan uji-t. Dari hasil penelitian tersebut, setelah diberi perlakuan menggunakan latihan pick-up sprint dan berlari dengan tenaga maksimal diperoleh nilai rata-rata post test $(12,53)$. Hasil uji hipotesis memberikan thitung $=13,62$ dan ttabel $=3,18$ dengan $a=0,05$ yang berarti Ho ditolak dan Ha diterima. Dengan demikian dapat disimpulkan bahwa secara signifikan latihan sprint pick-up dan lari dengan tenaga maksimal berpengaruh terhadap peningkatan kecepatan lari $100 \mathrm{~m}$ atlet putra atletik atletik unimed $100 \mathrm{~m}$ tahun 2020.
\end{abstract}

Kata Kunci: Atletik, Pick-up Sprint dan lari dengan tenaga maksimal.

\begin{abstract}
This study aims to determine whether there is an effect of pick-up sprint training and running with maximum effort on the speed results of male athletes in athletics running $100 \mathrm{~m}$ club unimed in 2020. The method used in this study is an experimental method with the implementation of exercises, namely pick-up sprint and run with maximum effort. The population is all male athletes running the $100 \mathrm{~m}$ unimed club in 2020, totaling 4 people. Samples were taken from the population with a total sampling technique. The sample taken from this study was 4 people. Research instrument for data collection with tests and measurements of the $100 \mathrm{~m}$ run test. The study was carried out for 6 weeks with 3 times a week of exercise. To see each independent and dependent variable, the t-test calculation is used. From the results of the study, after being treated using pick-up sprint training and running with maximum effort, the post-test average score was obtained (12.53). Hypothesis test results give tcount $=13.62$ and
\end{abstract}


ttable $=3.18$ with $\mathrm{a}=0.05$, meaning that Ho is rejected and Ha is accepted. Thus it is concluded that significantly the sprint pick-up training and running with maximum effort have an effect on the increase in the $100 \mathrm{~m}$ running speed of male athletes in the $100 \mathrm{~m}$ unimed club athletics in 2020.

Keywords: Athletics, Pick-up Sprint and running with maximum effort.

\section{PENDAHULUAN}

Atletik Adalah olahraga yang dalam setiap gerakannya menggunakan aktivitas fisik jasmani, dimana dalam melakukannya seluruh anggota tubuh akan ikut bergerak, baik itu kaki, tangan atau anggota tubuh lain (Parwata, I. M. Y., 2017). Atletik didalamnya termasuk bidang-bidang berikut: jalan, lari, lompat, lempar lembing, dan tolak peluru. Atletik yang kini merupakan inti dalam olimpiade adalah jenis olahraga yang menjadi dasar bagi kebanyakan jenis olahraga lainnya (Sujiono Soemaredjo, B., 2021).

Latihan atletik merupakan sarana baik sekali meningkatkan kemampuaan tubuh untuk berprestasi secara umum. Aktivitas gerak lari sprint dibagi atas beberapa tahap, yaitu: start, berlari ssecepatnya, mempertahankan kecepatan dan mencapai garis finish (Putra, A., dkk, 2020). Lari cepat atau lari jarak pendek sering dikatakan (sprint) adalah semua perlombaan lari dimana peserta berlari dengan kecepatan maksimal sepanjang jarak yang ditempuh.
Lari jarak pendek atau sprint adalah semua jenis lari yang sejak start sampai finish dilakukan dengan kecepatan maksimal. Salah satu nomor lari sprintadalah lari $100 \mathrm{~m}$. Lari sprint $1000 \mathrm{~m}$ berbeda dengan dengan lari $200 \mathrm{~m}$ atau 400 m Karena pada lari 100 m. harus dilakukan dengan kecepatan maksimal sepanjang lintasan. Lari cepat atau sprintmerupakan salah satu nomor dalam cabang olahraga atletik cukup bergengsi dimana baru-baru ini Muhammad Johri telah mengharumkan nama bangsa Indonesia dengan meraih mendali emas nomor lari $100 \mathrm{~m}$ pada aja IAAF U-20.

Johri mengalahkan wakil dari negaranegara unggulan dan menjadi atlet Indonesia pertama yang meraih medali emas pada IAAF U-20 Dengan catatan waktu 10,18 detik, johri unggul 0,04 detik dari runner up Antohny Schwartz (Amerika Serikat) dan juara 3 Eric Harrison (AS). Sebelumnya, Johri mengharumkan nama Indonesia dipentas atletik regional dan global. Sebelum keberangkatannya ke Finlandia, dia baru saja mengikuti kejuaraan Atletik Yuior 
Asia, di Gifu, Jepang. Johri sukses meraih medali emas setelah berhasil menaklukkan pelari dari beberapa Negara lainnya.

Lari 100 meter ini sangat mebutuhkan bentuk latihan yang mampu meningkatkan hasil kecepatan dalam latihan fisik sangat dibutuhkan dan sangat penting untuk mencapai prestasi yang sangat memuaskan dan diinginkan, dimana di setiap perlombaan yang dapat menghasilkan juara dalam perlombaan lari 100 meter (Datang, W., \& Pribadi, M. R., 2020). Jadi, kecepatan bukan hanya berarti menggerakan seluruh tubuh dengan cepat, akan tetapi dapat pula terbatas pada menggerakan anggota-anggota tubuh, seperti lengan, tungkai dalam waktu yang singkat-singkatnya (Sihombing, S., 2019).

Daya ledak adalah kemampuan otot untuk mengatasi tahan dengan kontraksi yang sangat cepat. Sehingga untuk memberikantenaga pada tungkai dengan cepat dan kuat dalam waktu yang sangat singkat seta memberikan momentum sebaik mungkin pada tubuh. Dengan demikian untuk meghasilkan kecepatan lari 100 meter memerlukan daya ledak otot tungkai Selain itu, apabila kondisi fisik atlet dalam keadaan baik, maka ia akan lebih cepat pula menguasai teknik-teknik gerakan yang dilatihkan.
Club Atletik Unimed yang di latih coach Sinung Nugroho M. Or. Alamat Jln. William Iskandar Muda Kecamatan Medan Baru,kota Medan, Sumatra Utara. Atlet Latihan di stadion atletik Unimed ini sebanyak 3 (tiga) kali dalam seminggu. Ketika peneliti melakukan pengamatan atau observasi pada hari dan tanggal Selasa 27 dan Jumat 30 Juni, Tahun 2019dan dilanjutkan Senin 2 - 6 Juli, Tahun 2019 di club atletik Unimed yang dilatih oleh coach Sinung Nugroho M.Or Serta melakukan wawancara sama pelatih menyatakan prestasi mereka sudah lumayan bagus dari perlombaan yang pernah di ikuti, misalnya PORKOT, dan PORWIL.Tapi atlet masih perlu ditingkatkan prestasi atlet tersebut. Saat observasipeneliti mendapati terdapat kelemahan dan kekurangan dalam melakukan sprint 100 meter yaiu hasil kecepatan sprint 100 meter yang masih kurang baik sehingga tidak dapat hasil yang maksimal.

Dari hasil observasi sementara atlet tersebutmemiliki hasil kecepatan lari 100 meter masih kurang maksimal.Atlet telah menguasai teknik lari 100 meter, tetapi atlet hanya meguasai tekniknya saja sehingga kecepatanlari 100 meter kurang memiliki hasil kecepatan yang maksimal.Dugaan dari hasil pengamatan dan 
wawancara pelatih, yang menyebabkan kurangnya hasil kecepatan adalah kurangnya latihan fisik lari 100 meter yang diberikan pelatih untuk menigkatkan hasil kecepatan sprint 100 meter. Untuk mendapat data yang benar peneliti melakukan tes pendahuluan untuk meguatkan penjelasan.

Dari hasil tes pendahuluan dapat disimpulkan terdapat masalah hasil kecepatansprint 100 meter jika dibandingkan denganhasil norma kecepatan lari 100 meter, padahal dalam lari 100 meter kecepatan sangat penting artinya kecepatan lari 100 meter yang dilakukan pada saat latihan masih perlu ditingkatkan dengan bentuk-bentuk latihan fisik lari 100 meter agar memeperoleh hasil yang baik dalam latihan yang dilakukan.

Sehubung dengan masalah diatas, maka peneliti tertarik untuk melakukan penelitian tentang "Pengaruh Latihan Pickup sprints dan Lari dan Usaha Maksimal Terhadap Hasil Kecepatan Atlet Putra Atletik Lari 100 Meter Club Unimed Tahun 2020"Namun untuk mencapai kecepatan agar lebih baik lagi peneliti mencoba memberikan latihan yang dapat meningkatkan hasil kecepatan lari 100 meter.

\section{METODE PENELITIAN}

Metode penelitian yang digunakan adalah metode experiment (Dwi, D. R. A. S., Asmawi, M., Wasan, A., \& Widiastuti, W., 2018). Dengan teknik pengambilan data yang melibatkan satu variabel terikat, dua variabel bebas, yaitu latihan pick-up sprint dan lari dengan usaha maksimal dan satu variabel terikat yaitu hasil kecepatan lari 100 meter.

Sampel yang diperoleh di berikan tes awal lari 100 meter kemudian diberikan latihan pick-up sprint dan lari dengan usaha maksimal selama 18 kali pertemuan. Setelah perlakuan berakhir, maka di lakukan tes akhir lari 100 meter. Yang menjadi populasi penelitian ini adalah atlet Club Atletik Unimed yang berjumlah 4 orang. Sampel yang diambil dari penelitian ini adalah 4 orang.

Tabel 1. Populasi

\begin{tabular}{llcl}
\hline No & Nama & Usia & \multicolumn{1}{c}{ Prestasi } \\
\hline 1. & $\begin{array}{l}\text { Ayub Niti } \\
\text { Raharja }\end{array}$ & $\begin{array}{c}20 \\
\text { Tahun }\end{array}$ & $\begin{array}{l}\text { Pomnas } \\
\text { juara 3 } \\
\text { tahun 2017 }\end{array}$ \\
\hline 2. & Safuan & $\begin{array}{c}20 \\
\text { Tahun }\end{array}$ & $\begin{array}{l}\text { Pomnas } \\
\text { juara 2 } \\
\text { tahun 2016 }\end{array}$ \\
\hline 3. & Andika & $\begin{array}{c}\text { 21 } \\
\text { Tahun }\end{array}$ & $\begin{array}{l}\text { Pomnas } \\
\text { juara 3 } \\
\text { tahun 2015 }\end{array}$ \\
\hline 4. & Risky & $\begin{array}{c}20 \\
\text { tahun }\end{array}$ & - \\
\hline
\end{tabular}


Desain penelitian yang digunakan adalah Pre test dan Post test, artinya sebelum diberikan perlakuan terlebih dahulu diadakan tes awal dan setelah perlakuan tiga kali seminggu selama 6 minggu (18 kali pertemuan). Adapun desain penilitiannya adaalah sebagai berikut:

\begin{tabular}{|c|c|c|}
\hline Pre test & $\begin{array}{c}\text { Treatment } \\
\text { (perlakuan) }\end{array}$ & Post test \\
\hline $\begin{array}{l}\text { Hasil } \\
\text { kecepatan } \\
\text { lari } 100 \\
\text { meter }\end{array}$ & $\begin{array}{l}\text { Test latihan } \\
\text { Pick-up sprint } \\
\text { dan Latihan } \\
\text { lari dengan } \\
\text { usaha } \\
\text { maksimal }\end{array}$ & $\begin{array}{l}\text { Hasil } \\
\text { kecepatan } \\
\text { lari } 100 \\
\text { meter }\end{array}$ \\
\hline
\end{tabular}

Dari sampel yang digunakanakan mendapat latihan yang sama yaitu latihan lari Pick-up sprint dan lari

\section{HASIL DAN PEMBAHASAN}

Berdasarkan hasil perhitungan yang dilakukan maka diperoleh pengujian hipotesis $t_{\text {hitung }}$ sebesar 13.62. Selanjutnya harga tersebut dibandingkan dengan harga $\mathrm{t}_{\text {tabel }}$ dengan $\mathrm{dk}=\mathrm{n}-1(4-1=3)$ pada taraf signifikan $\alpha=0,05$ adalah 3.18 dengan demikian $t_{\text {hitung }}>t_{\text {tabel }}(13,62>3.18)$. Hal ini berarti $\mathrm{H}_{0}$ ditolak dan $\mathrm{H}_{\mathrm{a}}$ diterima. Dengan demikian dapat disimpulkan bahwa terdapat pengaruh secara signifikan darilatihan pickupsprint dan lari dengan usaha maksimal terhadap hasil kecepatan atlet putra atletik lari 100 m club unimed tahun 2020. Dari hasil pengujian hipotesis menunjukkan bahwa terdapat pengaruh yang signifikan dari latihan pick-up sprint dan lari dengan usaha maksimal.

Hal ini menunjukkan bahwa adanya peningkatan hasil kecepatan lari $100 \mathrm{~m}$ pada atlet putra atletik Unimed tahun 2020 yang dilatih dengan latihan pick-up sprint dan lari dengan usaha maksimal. Artinya semakin baik latihan tersebut dilakukan semakin memberikan pengaruh hasil kecepatanlari $100 \mathrm{~m}$. Dari hasil pengelolahan data yang dilakukan dapat dilihat bahwa bentuk latihan Pick-up Sprint dan Lari Dengan Usaha Maksimal berpengaruh terhadap hasil kecepatan lari 100 meter.

Dalam lari sprint, kecepatan larinya ditentukan oleh gerakan berturut-turut dari kaki yang dilakukan secara cepat. Daya ledak tungkai merupakan perpaduan antara kecepatan dan kekuatan pada tungkai. Daya ledak tungkai sangat penting disetiap aktifitas pada cabang olahraga terutama yang mengharuskan menggunakan tungkai dalam aktivitas berolahraga (Sihombing, S., 2019).

Bentuk Latihan Pick-up Sprint dan lari dengan usaha maksimal ini memberikan pengaruh karena dilakukan berulang-ulang 
sesuai dengan program latihan seperti dikemukakan oleh Harsono (2018): "latihan adalah proses yang sistematis dan berlatih atau bekerja, yang dilakukan secara berulang -ulang dengan kian nambah baban latihan atau pekerjaannya (Harahap, L. H., \& Sulastio, A., 2021).

Hasil pengujian hipotesis menunjukan bahwa Latihan Pick -up Sprint dan Dengan Usaha Maksimal memberikan pengaruh yang signifikan terhadap hasil kecepatan lari 100 meter atlet putra club Unimed 2020. Seorang sprinter harus memiliki potensipotensi sebagai berikut : Memiliki frekuensi gerakan kaki yang tinggi, Memiliki mobilitas gerak yang baik, Memiliki kemampuan lari dengan condong, tolakan kaki kedepan yang baik, Memiliki kepercayaan terhadap kemampuan sendiri dan Memiliki hasrat untuk berlatih dengan tekun dan semangat untuk menang.

Latihan Pick-up Sprint adalah latihan kecepatan: kun pertama, jogging $50 \mathrm{~m}$ kun kedua, jogging lebih cepat $50 \mathrm{~m}$ kun ketiga, sprint kun keempat, jalan $50 \mathrm{~m}$ yang telah diberi jarak. Latihan ini memaksa atlet untuk meningkatkan kecepatan pada saat melewati kun yang sudah diberi jarak $50 \mathrm{~m}$ yang dapat menghasilkan kecepatan lari atlet bertambah Latihan ini akan memberikan potensi-potensi yang baik untuk atlet (Muhyi, M., \& Rosmi, Y. F., 2021).

Latihan Lari dengan Usaha maksimal adalah lari dengan kecepatan maksimal sampai tidak mampu berlari lagi. Latihan ini mampu melihat jarak lari atlet pada saat melakukan latihan ini Latihan Pick up Sprint dan Lari Dengan Usaha maksimal jika dilatih secara berulang-ulang maka dapat memberikan pengaaruh terhadap Hasil kepatan lari 100 meter (Dwi, D. R. A. S., Asmawi, M., Wasan, A., \& Widiastuti, W., 2018).

Kondisi fisik atlet memegang perananyang sangat penting dalam program latihannya. Program latihan kondisi fisik haruslah direncanakan secara baik dan sistematis dan ditujukan untuk meningkatkan kesegaran jasmani dan kemampuan fungsional dari sistem tubuh sehingga demikian memungkinkan atlet untuk mencapai prestasi yang lebih baik (Devi Catur Winata, dkk, 2020).

Secara psikologis pun ada keuntungannya. Karena atlet yang memiliki kondisi baik, biasanya juga merasa lebih percaya diri dan lebih siap dalam menghadapi tantangan - tantangan latihan dan pertandingan (Farda Kurniawan, dkk, 2020). Sistem serta bentuk latihan setiap unsur fisik, harus sesuai/ tepat (valid) untuk 
melatih setiap unsur tersebut. Oleh karena itu, haruslah dipahami terlebih dahulu batasan atau definisi setiap unsur fisik tersebut.

\section{KESIMPULAN}

Berdasarkan hasil pengujian hipotesis dan pembahasan hasil penelitian, maka peneliti dapat menarik kesimpulan bahwa latihan pick-up sprint dan ari dengan usaha maksimal memberikan pengaruh yang signifikan terhadap hasil kecepatan atlet putra atletik lari $100 \mathrm{~m}$ club unimed tahun 2020. Berdasarkan hasil penelitian dan kesimpulan, maka peneliti menyarankan sebagai berikut : Agar pelatih memberikan latihan pick-up sprint dan lari dengan usaha maksimal karena sama-sama berpengaruh untuk hasil kecepatanlari 100 m., Agar para peneliti selanjutnya melakukan penelitian lanjutan dengan menggunakan sampel yang lebih besar, waktu penelitian yang lebih lama dan program latihan yang baik., Kepada para atlet disarankan agar lebih bersungguh-sungguh dalam latihan. Kepada para pelatih agar memperhatikan bentuk latihan dalam program latihan yang di buat sesuai dengan tujuan yang ingin dicapai.

\section{DAFTAR PUSTAKA}

Datang, W., \& Pribadi, M. R. (2020). Hubungan Antara Panjang Tungkai dengan Kecepatan Lari 100 Meter pada Mahasiswa Putra Program Studi Pendidikan Olahraga (STKIP) Kie Raha Ternate. JURNAL PENDIDIKAN OLAHRAGA, 10(2), 1-9.

Devi Catur Winata, Muhammad Fahmi, \& Andi Nur Abady. (2020). Influence of Play Approach Against Sprint Learning Outcomes. JPJ (Jurnal Pendidikan Jasmani), 1(1), 8-13. Retrieved from http://jurnal.stokbinaguna.ac.id/index .php/JPJ/article/view/109.

Dwi, D. R. A. S., Asmawi, M., Wasan, A., \& Widiastuti, W. (2018). Pengaruh Metode Latihan Dan Power Tungkai Terhadap Peningkatan Kecepatan Akselerasi Sprint. JUARA: Jurnal Olahraga, 3(2), 62-69.

Farda Kurniawan, Danang Ari Santoso, \& Wawan Setiawan. (2020). Analisis Psikologi Terhadap Kepercayaan Diri Atlet Sepakbola. JPJ (Jurnal Pendidikan Jasmani), 1(2), 47-58. https://doi.org/10.2245/jpj.v1i2.126.

Harahap, L. H., \& Sulastio, A. (2021). Kontribusi daya ledak otot tungkai terhadap kemampuan lari sprint 100 meter. Journal Athletic and Sport Nutrition, 1(1), 30-37.

Harsono. (2018). Latihan Kondisi Fisik. Bandung: PT. Remaja Rosda Karya.

Muhyi, M., \& Rosmi, Y. F. (2021). Pengembangan Model Latihan Garuda Dalam Meningkatkan Kelincahan Pemain Futsal $\mathrm{Ku}$ - 
Pengaruh Latihan Pick-Up Sprint Dan Lari Dengan Usaha Maksimal terhadap Hasil Kecepatan Lari 100 Meter Atlet Putra Atletik Club Unimed Tahun 2020

\section{Jurnal Pendidikan Jasmani} Khatulistiwa, 2(1), 1-8.

Parwata, I. M. Y. (2017). Hubungan Tinggi Badan dan Berat Badan terhadap Kecepatan Lari 100 Meter Mahasiswa Putra Fpok IKIP PGRI Bali. Jurnal Pendidikan Kesehatan Rekreasi, 3(2), 19-27.

Putra, A., Aziz, I., Mardela, R., \& Lesmana, H. S. (2020). Tinjauan Kecepatan Lari 100 Meter Siswa Sma. Jurnal Patriot, 2(4), 940-950.

Sihombing, S. (2019). Hubungan Panjang Tungkai Dan Daya Ledak Otot Tungkai Dengan Hasil Lari Sprint 100 Meter. Kinestetik: Jurnal Ilmiah Pendidikan Jasmani, 3(2), 256-261.

Sujiono Soemaredjo, B. (2021). Studi Literasi Tentang Frekuensi Langkah Dan Panjang Langkah Pada Kecepatan Lari Sprint 100 Meter. Jurnal Ilmiah Sport Coaching and Education, 5(1), 25-31. 